\title{
Modern Architecture, Spatial Precarity and the Female Body in the Domestic Spaces in Iran
}

\author{
Ladan Rahbari ${ }^{1 *}$
}

${ }^{1}$ Ghent University, BELGIUM

*Corresponding Author: Ladan.Rahbari@UGent.be

Citation: Rahbari, L. (2016) Modern Architecture, Spatial Precarity and the Female Body in the Domestic Spaces in Iran, European Journal of Sociology and Anthropology, 1:2 (2016), 2. doi:10.20897/ ejsa.201602

Received: August 28, 2016; Accepted: December 10, 2016; Published: December 25, 2016

\begin{abstract}
Iranian home is used as private, semi-private and public spaces. It has kept its traditional functions despite alterations in its structure and is a space for women to engage in caretaking and housekeeping activities. In this paper, I will discuss how modern architecture and its consequences such as the deletion of women-only spaces called Andarooni, has not acknowledged women's appropriation of the domestic space as it is not conformed to the Iranian lifestyle and patterns of social relations. Using ethnography, participant observation and informal conversations with Iranian women, I investigate the characteristics of the contemporary home which reveal how disappearing privateness of the domestic space has contributed to women's precarious bodily freedom in domestic spaces.
\end{abstract}

Keywords: architecture, gender, private, public, space

\section{INTRODUCTION}

Virginia Woolf's (2004) piece, 'A Room of one's own' was one of the first widely-read texts which acknowledged the importance of the relationship between space and human creativity. Along with the article's discussion on women's literary traditions in a patriarchal context, Woolf (2004) noted the importance of access to private space and its impact on women's sense of belonging and creativity. Although her piece was a fictional narrative and an important literary piece of work, it also bore theoretical importance due to an accurate theorization of women's historic relation to the space. Today, about a century after the publication of Woolf's essay, in many social contexts around the globe, the problem of appropriation of space persists.

Space allocation is a challenging problem in the lives of Iranian women and perhaps women elsewhere. Although realization of right to the space has also not been fulfilled for other marginal class and ethnic groups, the gender dimension is still a significant issue. Not only gendered politics of space allocation, but also spatial design and architecture play a role in how the space is perceived to a specific group, such as a gender group (Rahbari and Sharepour, 2015; Knox and Pinch, 2010: 134).

In the traditional categorization of space in the Iranian context, home was made up of several sections. The most private part Andarooni was a space in which women and young children were settled and outsiders and male visitors could not enter (Kazemi, 2009). Andarooni was frequently visited by the male inhabitants of the house and rarely by few other men such as fathers, brothers, children, etc. This division of space showed architecture's complicity with gender power relations and social roles in creating a symbolic system of representation of gender power hierarchies (Torre, 2003: 141). The other major section of the house was Birooni, dedicated to larger and more public gatherings, visits, and other use by the male inhabitants of the house.

This spatial setting changed after the modernization of country in early twentieth century. In the same period, women's presence in public sphere was gradually normalised. Iranian women entered the public sphere and 
engaged in activities taking place outside the house during the Iranian early modern period. Since the 1940s, due to an increase in women's literacy, the number of working women saw a gradual increase.

With the increase of women's public participation, the disappearance of Andarooni seemed justified. modernization of society led to changes in architecture and theories of space design and management which eventually eliminated the Andarooni. Despite the elimination of the physical Andarooni, the modes of gendered social relation and allocation of space persisted (Rahbari, 2013) in a way that some anthropologists suggested that in fact women have been enjoying the freedom and the rights in the society, only in a factitive way (Nercissians, 2004: 186).

The changes in the house design and architecture and the imported concept of modern space have been applied in a context in which women are perceived to be belonging to a secure private sphere and a safe space inside the house; thus, the Iranian home is still defined by the division of gendered labour and the social distance between women and the outsiders is a prevalent predictor of how and where social interactions take place.

In this article, by using ethnography and participant observation, I focus on the contemporary Iranian home and its implications for women and women's bodily presence and representations in everyday practices in the domestic space. I also address the impacts of modern architecture in the formation of the new domestic space and discuss how it has changed female presence, movement and behaviour by changing the privateness of the house. To do this, the characteristics of the modern Iranian house which affect the everyday practices in the cultural and religious context of Iranian society are discussed.

\section{METHOD}

This research is conducted using ethnographic and participant observation methods. I have also had several informal conversations with Iranian women to bolster and test my findings. The idea of this research was developed through personal experience of living in urban Iran and observing how women's bodily practices in domestic spaces change according to who was present in the space and how women perceived their social distances from others. Most of the ethnographic and participant observation was conducted during the Persian New Year visitations between 21 February to 1 April 2014. Ethnography was based on direct engagement and involvement in the social interactions and maintaining a natural context (Le Compte and Goetz, 1982).

During the New Year celebrations, as a part of Iranian customs and social etiquette, families pay visit to their relatives', close friends' and colleagues' houses by turn. Each visit, is paid back by a visit; so, the visits are also reciprocal and it is not acceptable to ignore a pay-back visit; meaning that each party needs to visit all relatives, and then be visited by them. The custom is that visiting relatives takes place based on their status and age; the higher the status and age, the sooner they get visited. However, the visits are not done with a previous arrangement and there is no need to notify the host unless you are staying over-night. Hence, if you pay a visit to someone and they are not home, you can leave a note at their entrance/door; and the absent host will owe you a visit after receiving the note. The whole process happens during the first twelve days of the Persian New Year. Although there are different traditions of New Year preparations in different areas of the country, this visitation custom is universally observed by Iranians. My visits to family and friends' houses provided ample opportunity for me to observe how women managed their bodies and movements. I paid a total of nine visits and was visited by eight visitors. I had conversations with the participants about the implications of these unexpected and unscheduled visitors on how they perceived their spaces and how they managed their bodies in the spaces of their house.

\section{RESEARCH BACKGROUND}

\section{Architecture, female body and private space}

One of the valuable classic studies on the relationship between architecture, space and gender is the study conducted by Pierre Bourdieu (1990) on the Kabyle house. Bourdieu emphasized on the significance of gender in the division of the space and the categorization of the space to interior and exterior sections. He defined gender as the fundamental factor in the spatial settings of the Kabyle house and discussed that the symbolic perception of space is different depending on whether the subject is male or female (Lane, 2000: 98).

Vom Bruck's (1997) usage of Bourdieu's findings and his study in the Yemeni house suggested a different gender approach. He showed that unlike the Kabyle house, in the Yemeni house no obvious barriers were drawn between the interior and the exterior; in fact, it was the actual presence or absence of social actors' practices in the space and time frames that define the privateness and the publicness of a house. He also found out that other social factors such as age and social status were effective in the perceptions of the space. 
While Bourdieu's findings were similar to the traditional Iranian model of separating Andarooni and Birooni, Vom Bruck's (1996) discussion on the lack of distinct boundaries between interior and exterior represent the contemporary model of space division.

In contemporary Iran, the implementation of the longstanding private/public sphere duality as discussed by Engels (2004) has created two distinct spheres of social practice based on gender. The domestic or private sphere is widely perceived to be the feminine sphere, or women's space because of women's roles as primary caregivers, and the public sphere is considered the masculine sphere as the primary breadwinner (Fakouhi, 2005).

Since the introduction of Western modern concepts of architecture to the Iranian context, it has proved to be problematic due to its opposition to the local prevalent approaches (Al-Asad, 2007). Marefat (2007) has mentioned that the interlinking various modern and traditional factors shape the new Iranian architecture and space. Shaefer (2002) has also noted that in many contemporary cities, processes and dynamics of change and development integrate with the local and indigenous histories and create a mosaic of religion, economic resources, communication forms and politics. This ever-growing and fast urbanization and the development of technology in the twentieth century has caused standardization and homogenization of the built environment, including domestic space and home design and has contributed to the destruction of the cultural forms and the human ecosystem (Shaefer, 2002).

Following the socio-economic changes of the late nineteenth and early twentieth century, the formation of new schools of architecture brought about novel patterns of home and domestic space design which included new and altered functions for the domestic space. This new design style was appropriate for making optimal use of small spaces. This approach rationalized the domestic space and tried to optimally functionalize the spaces. It not only changed the urban public spaces but also dramatically changed the new domestic space compatible to the new modern ways of life (Fazeli, 2006). Thus, today Iranian architects usually find themselves in the middle of two opposing forces rooted in the present and past ideas, culture, and architecture schools which shape their artistic values and modes of expression (Eldemeri, 2009: 343).

The first wave of modernization of architecture assumed features such as smallness, simplicity, optimal usage of the space, lack of colours and symbols, and functional division for the domestic space. In this modern approach, the new home was also a smaller and simpler unit (Fazeli, 2006) with limited functions. The reductionist approach to the new house saw it solely as a residential unit, unlike some theorists such as Ruskin who expected much more than providing a residential space from the domestic space (Ghaznavian, 2013). Despite such oppositions, mostly due to the vast changes in the population and the urban contexture, especially in relatively big cities and metropolitan areas, applying the criteria suggested by the modern movement such as simplicity, smallness and optimal usage of space seemed inevitable. But in the context of Iran, modern architecture was embraced not only due to environmental and demographic factors, but also because it was compatible with waves of Western intellectualism and acceleration of importing Western concepts to the country (Ghobadian and Kiani, 2013).

\section{Iranian home, privateness and the rule of Mahram}

The private domestic space has the functions of separation, representation and protection. It has the function of socialization in common with other social institutions. Home is a physical reality and a subjective concept, perception of which is in permanent relationship with memories and experiences and cultural contexts and practices (Eldemeri, 2009).

The Iranian domestic space is historically a sanctum with principles that are pre-established in the society, a sanctuary for the family, private matters and reproductive work (Akrami and Zare, 2013). This house, just as Bourdieu (1990) has suggested in a similar context, is a result of gender roles and practices. One of these principles is that, it is not acceptable for the male Non-Mabram to enter it in the absence of the male proprietors, or residents. Non-Mahram is a term derived from the Islamic culture which refers to people of the opposite sex whom a person must abstain from certain physical contacts. The permanent or blood Mahram with whom one is Mahram by a blood relationship are parents, grandparents and further ancestors' siblings, children, grandchildren and further descendants' siblings of parents, grandparents and further ancestors' children and further descendants of siblings. In-law Mahram with whom one becomes Mahram by marrying someone include father-in-law, mother-in-law; sonin-law, daughter-in-law, stepfather, stepmother; stepson, and stepdaughter (wife's daughter). The Mahram category includes a group of men with whom women have certain family relations, and the rest of the men are considered Non-Mahram to them. Sometimes a guest is Mahram to one female resident but not to others; for instance, a woman's nephew is Mahram to her, but not to her daughter, since cousins are not considered Mahram in the Islamic culture.

In case of women's behavior in the presence of non-Mahram the traditional rules of interaction include certain religious and cultural guidelines for body management and movement. Although it can be discussed that female practices of body covering have a longer history than Islamic era in the Persian history (e.g. Mahbobimanesh, 2008), the contemporary form of veiling is based on the Islamic tradition. This means that changes in spatial 
relations, do not only affect gendered inhabitance but also bodily practices, movement, and the ways a woman talks, walks, laughs and interacts with others.

The Non-Mahrams presence in the house suspends the privateness of the house and turns it into semi-private or public space. The new house or apartment built by the modern standards of home building in Iranian context is prone to constant shift in the extent of privateness for women, as the provisioned functions of this space and gendered practices in the house become disrupted by the presence of male guests or other intrusions by NonMahram visitors.

\section{Home architecture, barriers and bodily display}

In traditional Islamic tradition, not only social principles have played an important role in controlling the spatial interaction between family members and 'others', but these rules are also embodied in the residence design (Ferwati, 2013). In traditional Iranian architecture barriers (e.g. doors and walls) and connectors (e.g. hallways and stairs) have served as means to produce sense of separation between spaces (Soltanzade, 2005; Asgharzade and Mobaraki, 2015; Akrami and Zare, 2013). The difference between a barrier and a connector/hall was that barriers were physical delimiters while hollow connectors symbolically gave the feeling of separation and obliged the NonMahram to avoid passing them.

The need to reduce construction costs and efficiently use small spaces has led to the simplification of domestic space designs and elimination of all barriers, while at the same time flattening of the space has led to omission of stairs and differences in surface altitude. Creating open structures, such as the elimination of the barriers between the kitchen and other rooms of the house (usually the living room) has been a common practice to optimize the light and the space in the modern home design.

In traditional Iranian home design, the kitchen was not a part of Birooni but a private space for women to work in, the open kitchen layout has maximized women's exposure to the existing eyes. In fact, the traditional Iranian Kitchen was mostly placed in the basement or in the corner of the yard, or it was placed between the Andarooni (private part) and the Birooni (public part) spaces of the house (Akrami and Zare, 2013). This has had significant impact on the perceived size of the space and is therefore widely welcomed in the modern house design, especially in smaller houses and apartments. This form of design allows the kitchen to be seen from other rooms of the house which welcome guests including the Non-Mahram. As a consequence, the kitchen which has long been a space in which women could freely move and work without being concerned about being seen with the help of barriers such as walls, stairs or curtains, is now a part of the semi-public space. This means that women have to apply the same rules of behaviour, body management and movement as they do in public spaces.

The kitchen has traditionally been and still is where women would gather during ceremonies, celebrations, and family events. This elimination of barriers between the kitchen and semi-private spaces of the house, has happened regardless of the fact that values on women's roles and female modesty have not seen great change in the context of Iranian society. During the new year's visitation, women have to work in the kitchen while being exposed to visitors' eyes. The informants of this study perceived this to be problematic because the kitchen needed to be constantly cleaned; they had to appear with clothes appropriate for the public space which were at times disturbing because it limited their movements as well as making them uncomfortable due to high temperatures in the kitchen.

Another principle of modern architecture has been to remove spaces which formerly worked as hollow connectors between the functional spaces of the house in order to optimize usage of space, while these played an important role in traditional Iranian architecture (Akrami and Zare, 2013). These Spaces such as hallways, corridors, doorways, lobbies etc. are avoided and reduced as much as possible to add extra volume to the main parts of the house such as the living room and the bedroom(s).

Studies on Islamic architecture such as O'Meara's (2007) study in Morocco and Akrami and Zare's (2013) study in Iran delineate the importance of corridors and hallways in creating the private space. O'Meara (2007) introduced the hallway as a passage that bore symbolic ethical meanings and connected the core of the house (the sacred spaces, Andarooni) to the outside and public world (Birooni). The elimination of barriers and connectors has led to the direct and sans-intermediary connection between the so-called main spaces of the modern house: sleeping area, cooking and eating area, sitting and hosting area, and bathroom. Today, in most urban area houses and apartments in Iran, in fact in all the houses I visited during my fieldwork, the bedroom door opens directly to the living room.

These changes in the spatial arrangements have affected women more than men. The modern arrangement of the domestic space increases the fluidity of privateness of spaces by eliminating traditional aspects of the Iranian house. Iranian domestic space emphasizes on a hosting area in which guests are welcomed and received. I observed that welcoming visitors is usually performed by male inhabitants of the house or by children because women have to immediately rush to the bedroom to change in to a more publicly 'proper' outfit upon guests' arrival or wear their hijab if they observe the religious norms of conduct in the presence of possibly Non-Mahram guests. 
Space is important because Iranian culture puts emphasis on family gatherings and continuous meet and greets with family members on different occasions such as religious and traditional Persian celebrations. With the transformations in the home design and disappearance of Andarooni, female residents of the house do not have a space of their own to interact with other female visitors. So, depending on the nature of the propinquity or familiarity, and cultural limits of interaction between the host and the guest, the privateness of the domestic space gets redefined. If the male visitor is considered Mahram to all female residents of the house, women can interact more easily; but if the male visitor is not Mahram to them, his visit brings about limitations in movement and usage of body management strategies for female residents of the house, sometimes changing the domestic space in to a public space. This does not merely limit the female inhabitants in terms of dress code, but also the ways they sit, talk, laugh, walk, etc. are affected by the presence of the Non-Mahram in the house.

\section{Private space and reproductive work}

For most of Iranian history, the domestic space has mainly been defined on the basis of gender relations and gendered representation of body (i.e. Seifian and Mahmoudi, 2007); since the works and activities in the house have mostly been done by women, and they have been spending more time in the house than men, the domestic spaces have been considered to be feminine. Although women spend more time in the domestic space than men in both tradition and modern societies (Jolly et al., 2014; Galinsky, Aumann and Bond, 2011; Ferrant, 2014), in the modern house design no space is specifically allocated to them. Women work in the house and spend most of their life in the domestic space, but none of the spaces in the house (in modern terms, living room, bedroom, bathroom, children's bedroom or kitchen) is a space for women, while in the traditional Iranian house design the Andarooni was specifically allocated to women (Zarjabad, Taghavi, Masoudi, 2015).

Women work in the domestic space but not only do they not have a space of their own; they often do not own it. So, the domestic space is considered 'feminine' merely because it is a space occupied by women, and because women have been historically the prominent workers in it (Rezeanu, 2015); but the space is not a women's space as there is no space appropriated by women for their own personal activities. This goes hand in hand with the effects of modern architecture, for which women's bodily freedom is dramatically reduced.

During my field work, I observed that women are the main and sometimes sole workers in the kitchen. It is common among men to lend a hand to their partners. Children, especially young girls, also usually help out with preparations of food and receiving guests; but it was dominantly women who prepared snacks, food and drinks and served them to guests. The most common practice of serving the guests was serving the food and drinks in trays and bending in front of the guests. In my conversation with the participants of the study, some women explained that since they spend most of their time at home working and serving during the holidays, they prefer to spend leisure outside the house in parks or shopping malls, while for their partners, home is a space of recuperation and leisure.

Discrepancies between the local culture and modern architecture have encouraged some social scientists to call the modern architecture in Iran 'identity-less' (Fakouhi, 2013). Fakouhi (2013) has noted that modern architecture in Iran bears no symbolic content, since the process of creating and choosing the form which includes choosing material frameworks to mobilize mentality in the time axis has taken place sometimes by complete separation and other times by the heterogeneity of the signifier and the signified; so, the forms are in contrast or incompatible with the discourse and the mentality they embed and are embedded in. Thus, the Iranian domestic space has dedicated its logic to be able to imitate the global trends of home and domestic space design.

\section{CONCLUSION}

In this paper, I discussed the impact of modern architecture on the domestic space and its limitations for women in Iran. I illustrated how the use of the modern small apartment as semi-private and sometimes public space, restricts women's freedom in using spaces. It seems that public spaces should create alternatives for some daily practices. The difference between the pre-modern and modern home design is that in the pre-modern discourse there was a specific space allocated. I also observed that the privateness of domestic space is always subject to change as it can easily convert to a semi-public or public space. The fluidity of the privateness affects women more than men, because according to the traditional, religious and cultural discourses, women should abstain from being exposed to the eyes of Non-Mahram, and follow a certain dress and behavioral code in public/semi-public spaces. So, any change in the shape, layout and privacy of the domestic space impacts women more than men.

The question of what can be done to reduce the effects of home architecture in women's lives relies on new approaches in home design which reflect women's views and perceptions and the complementarity of domestic and urban spaces. While it is possible to change the current male-oriented home design (Grosz, 2001), this resolution has its limitations. Thus, producing semi/private and multi/functional spaces in the city is an alternative 
way to possibly reduce the need for commuting long distances in the city for women and make the public spaces they have access to, safer and livelier. Avoiding the mono-functional space and creating diversity throughout the city will produce a sense of belonging to the public space (Jacobs, 2009). Architecture is one section of the overall urban contexture. The relationship between the private domestic space, the public urban space, the suburbs and the spaces of leisure and work spaces cannot be left to chance and are complementary in the social life. The spatial diversity model, brings about the proximity of residential, commercial, leisure, and work spaces in an urban context; it creates a better feeling and enables a variety of spatial experiences for diverse users (Ghaznavian, 2013). One of the main conditions for the realization of high quality urban everyday life is the multi-functionality of the city so that people can interact in the urban spaces at any time of the day (Sharepour, 2011: 217). The women's parks experience in Iran is one of the experiences which has successfully created a women's feminine space to replace the Andaroonis. These parks, located in different places in the city are single-gender spaces which provide natural, sports and leisure facilities. This kind of provision is important because in the modern mega-cities such as Tehran, the private space is shrinking and it is almost impossible to allocate a space to women, or 'a room of their own' inside the house. So, the one alternative solution would be to create spaces outside the house that produce the same feeling of appropriation and consider women's long ignored needs in the urban geography (UNESCO, 2011; Larimore, 1978). The everyday practices of appropriation and re-appropriation of the space leads to encountering and challenging the hegemonic concept of citizenship (De Certeau, 1984).

Although one might discuss that the cultural patriarchal values are the core of the problem of space and gendered spatial settings, it is important to note that as long as the cultural context has not adopted an egalitarian framework, changes in the social-spatial arrangements would facilitate women's everyday life.

\section{REFERENCES}

Al-Asad, M. (2007). The Contemporary Built Environment in the Arab Middle East. In: The Middle East Institute Viempoints: Architecture and Urbanism in the Middle East. [online] pp. 25-27. Available at: http://www.mei.edu/sites/default/files/publications/2008.11.Architecture $\% 20$ and $\% 20$ Urbanism $\% 20 \mathrm{in} \% 20$ the $\% 20$ Middle $\% 20$ East.pdf

Akrami, G. and Zare, F. (2013). Home Design in the Old City Districts: A Case Study in the Old District in Ghom (in Persian). Fine Arts-Architecture and Urban Design Journal, 18(2), pp. 55-68.

Asgharzade, A. and Mobaraki, H. (2015). Status of Women's Sanctuary in In-Between Spaces in Present and Past Architecture Traditions in Iran. In: The First National Conference of House Architecture. 5 February 2015, Malayer, Iran.

Bourdieu, P. (1990). The logic of practice. Stanford: Stanford University Press.

De Certeau, M. (1984). The Practice of Everyday Life. Berkeley: University of California Press.

Eldemeri, I.M. (2009). Globalization Challenges in Architecture. Journal of Architectural and Planning Research, 26(4), pp. 343-355.

Engels, F. (2004). The Origin of Family, Private Property and the State. Chippendale: Resistance Books.

Fakouhi, N. (2004). Urban Anthropology (in Persian). Tehran: Ney Publication.

Fakouhi, N. (2005). History of Anthropological Thoughts and Theories (in Persian). Tehran: Ney Publication.

Fakouhi, N. (2013). Anthropology of Art (in Persian). Tehran: Sales Publication.

Fazeli, N. (2006). House in Iranian Culture. [online] Available at: http://isa.org.ir/node/1185 [Accessed 26 January 2014].

Ferrant, G. (2014). Time Use as a Transformative Indicator for Gender Equality in the Post 2015 Agenda. [online] OECD development centre report. Available at: http://www.oecd.org/dev/poverty/Time\%20use\%20_final_2014.pdf [Accessed 26 January 2014].

Ferwati, S. (2013). Spatial Behavioral Aspects of the Arab Built Environment. International Journal of Physical and Human Geography, 1(1), pp. 1-9.

Galinsky, E., Aumann, K. and Bond, J. (2011). Times are Changing: Gender and Generation at work and at Home. [online] Families and work Institute Report, IBM corporation. Available at: http://familiesandwork.org/site/research/reports/Times_Are_Changing.pdf [Accessed 26 December 2015].

Ghaznavian, Z. (2013). Variety in Domestic Space. [online] http://anthropology.ir/node/19291 [Accessed 25 January 2014].

Ghobadian, V. and Kiani, M. (2013). Sources of Modern Architecture in Iran: Analysis of First Modern Architecture Designs in Tehran. Journal of Architecture and Urban Design [Farsi Journal], 11 (Fall and Winter), pp. 39-58.

Giedion, S. (2007). Space, Time and Architecture (in Persian), translated by Manochehr Mozayeni. Tehran: Elmi va Farhangi Publication.

Hayford, A. (1974). The Geography of Women: An Historical Introduction. Antipode, 6(2), pp. 1-19. 
Grosz, E. (2001). Architecture from the Outside Essays on Virtual and Real Space. Massachusetts: Massachusetts Institute of Technology.

Jacobs, J. (2009). The Death and Life of Great American Cities, translated by Hamidreza Parsi and Arezoo Aflatouni. Tehran: Tehran University Publications.

Jolly, S., Griffith, K., DeCastro, R., Ubel, P. and Jagsi, R. (2014). Gender Differences in Time Spent on Parenting and Domestic Responsibilities by High-Achieving Young Physician-Researchers. Annals of Internal Medicine, 160(5), pp. 344-353. doi:10.7326/M13-0974

Kazemi, M. (2009). Analytic Study of Gender and Its Effect on the Quality of Space. City's Identity [Farsi Journal], 3(4), pp. 47-58.

Knox, P. and Pinch, S. (2010). Urban Social Geography: An Introduction. Pearson: Prentice Hall.

Lane, J.F. (2000). Pierre Bourdieu: A Critical Introduction. London: Sterling, VA: Pluto Press.

Larimore, A. (1978). Humanizing the Writing of Cultural Geography Textbooks. Journal of Geography, 77, pp. 183185.

Le Compte, M.D. and Goetz, J.P. (1982). Problems of Reliability and Validity in Ethnographic Research. Review of Educational Research, 52(1), pp. 30-60.

Lévi-Strauss, C. (1987). Anthropology and Myth: Lectures 1951-1982. Oxford: Basil Blackwell.

Mahboobimanesh, H. (2008). Social Analysis of the Hijab Issue. Women's Book, 10(38), pp. 89-134. [in Farsi], Available at: http://www.sid.ir/fa/VEWSSID/J_pdf/48713863804.pdf

Marefat, M. (2007). Modernizing and De-Modernizing: Notes on Tehran. In: The Middle East Institute Viewpoints: Architecture and Urbanism in the Middle East, [online] pp. 52-56. Available at: http://www.mei.edu/sites/default/ files/publications/2008.11.Architecture $\% 20$ and $\% 20$ Urbanism $\% 20 \mathrm{in} \% 20$ the $\% 20$ Middle $\% 20$ East.pdf

Nercissians, E. (2004). Anthropology of Gender (in Persian). Tehran: Afkar Publications.

O’Meara, S. (2007). Labyrinth: Moroccan Medinas. In: The Middle East Institute Viewpoints: Architecture and Urbanism in the Middle East, [online] pp. 7-9. Available at: http:/ /www.mei.edu/sites/default/files/publications/2008.11.Architecture $\% 20$ and $\% 20$ Urbanism $\% 20$ in $\% 20$ the $\% 20$ Middle $\% 20$ East.pdf

Rahbari, L. (2013). Gender and Spatial Belonging. [online] Available at: http://anthropology.ir/article/21972 [Accessed 11 December 2016].

Rahbari, L. and Sharepour, M. (2015). Gender and Realisation of Women's Right to the City in Tehran. Asian Journal of Social Sciences, 43(3), pp. 227-248.

Rezeanu, C.I. (2015). The relationship between domestic space and gender identity: Some signs of emergence of alternative domestic femininity and masculinity. Journal of Cotmeporary Research in Sociology and Anthropology, 6(2), pp. 9-29.

Sajadpour, F. (n.d.) Women's Employment: History of their Participation in the Market and Higher Education (in Persian). [online] Available at: http://anthropology.ir/node/11956 [Accessed 13 October 2015].

Schaefer, W. (2002). Global Techno science: The Dark Matter of Social Theory. In: University of Maryland Conference on Globalizations: Cultural, Economic, Democratic, April 11, pp. 1.

Seifian, M.K. and Mahmoudi, M.R. (2007). Mahramiyat in Traditional Iranian Architecture. City's Identity, 1(1, Fall and Winter), pp. 3-14.

Sharepour, M. (2010). Urban Sociology (in Persian). Tehran: SAMT Publication.

Soltanzade, H. (2005). Entrances in Traditional Iranian Architecture. Tehran: Cultural Research Office Publications.

Torre, S. (2003). Claiming the Public Space: The Mothers of Plaza de Mayo, in Jane Rendell, Barbara Penner and Iain Borden. In: Gender, Space, Architecture: An Interdisciplinary Introduction, pp. 140-145, London and New York: Routledge.

UNESCO (2011). Urban Policies and the Right to the City in India: Rights, Responsibilities and Citizenship, [online] Available at: http://unesdoc.unesco.org/images/0021/002146/214602e.pdf [Accessed 7 August 2016].

Vom Bruck, G. (1997). A House Turned Inside Out: Inhabiting Space in a Yemeni City. Journal of Material Culture, 2(2), pp. 139-172.

Woolf, V. (2004). A Room of One's Own (in Persian), translated by Safoora Nourbakhsh. Tehran: Niloofar Publications.

Zarjabad, H., Taghavi, A. and Masoudi, Z. (2015). Introvertness and Reflection of Mahramiyat in Islamic Iranian Architecture. Khorasan Quaterly of Cultural and Social Studies, 9(2), pp. 123-146. 